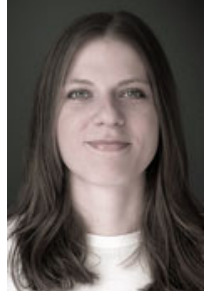

Annabel Mechela

Jahrgang 1991. 2010-2018 Studium der Biologie und Kommunikationswissenschaft an der LMU München. Seit 2018 Promotion im Fachbereich Pflanzenbiochemie in der Gruppe von Prof. Dr. J. Soll, LMU München.

DOI: $10.1007 / \mathrm{s} 12268-019-1009-\mathrm{y}$

(C) Springer-Verlag 2019

Chloroplasten sind durch primäre Endosymbiose entstanden, indem ein Vorfahre heutiger photosynthetischer Cyanobakterien von einer eukaryotischen Zelle aufgenommen wurde. Durch massiven Gentransfer in den Wirtskern wurde aus dem Endosymbionten über die Zeit ein zelluläres Organell. Aufgrund ihrer Abstammung von einem Gram-negativen Prokaryoten sind Plastiden von zwei Hüllmembranen umgeben. Außerdem befinden sich im Inneren der Chloroplasten die Thylakoide als ein weiteres komplexes Membransystem [1]. Die Thylakoidmembran ist eine dynamische, anpassungsfähige und spezialisierte Biomembran. In diese eingebettet sind hochmolekulare Proteinkomplexe, welche die lichtabhängigen Reaktionen der Photosynthese ermöglichen. Jedoch ist bislang nicht klar, welche Faktoren an der Entstehung der
ISE-G-Preis 2018

\section{Das grüne Shuttle - Vesikeltransport im Chloroplasten}

\author{
ANNABEL MECHELA \\ DEPARTMENT BIOLOGIE I - PFLANZENWISSENSCHAFTEN, BIOZENTRUM DER \\ LMU MÜNCHEN, PLANEGG-MARTINSRIED
}

Thylakoidmembran beteiligt sind und wie dieser Vorgang initiiert und reguliert wird.

Da sowohl Lipide an der inneren Hüllmembran gebildet werden als auch die meisten plastidären Proteine über diese Membran in den Chloroplasten eintreten, scheint eine Verbindung der Hüllmembran mit der entstehenden Thylakoidmembran sinnvoll. Häufige Beobachtungen von vesikulären Strukturen legen die Vermutung nahe, dass ein Vesikeltransportsystem, ähnlich wie es im Endomembransystem der Zelle vorzufinden ist, dafür verantwortlich ist [2]. Evolutionär gesehen besitzen nur Embryophyten (Moose, Farnartige, Samenpflanzen) ein solches Vesikelsystem, Cyanobakterien und Algen hingegen nicht. Daher ist es sehr wahrscheinlich, dass das plastidäre Vesikelsystem eukaryotischen Ursprungs ist und in das Organell übertragen wurde. Interessanterweise entwickelten sich Embryophyten gleichzeitig mit dem schwierigen Übergang zu einem Leben außerhalb des

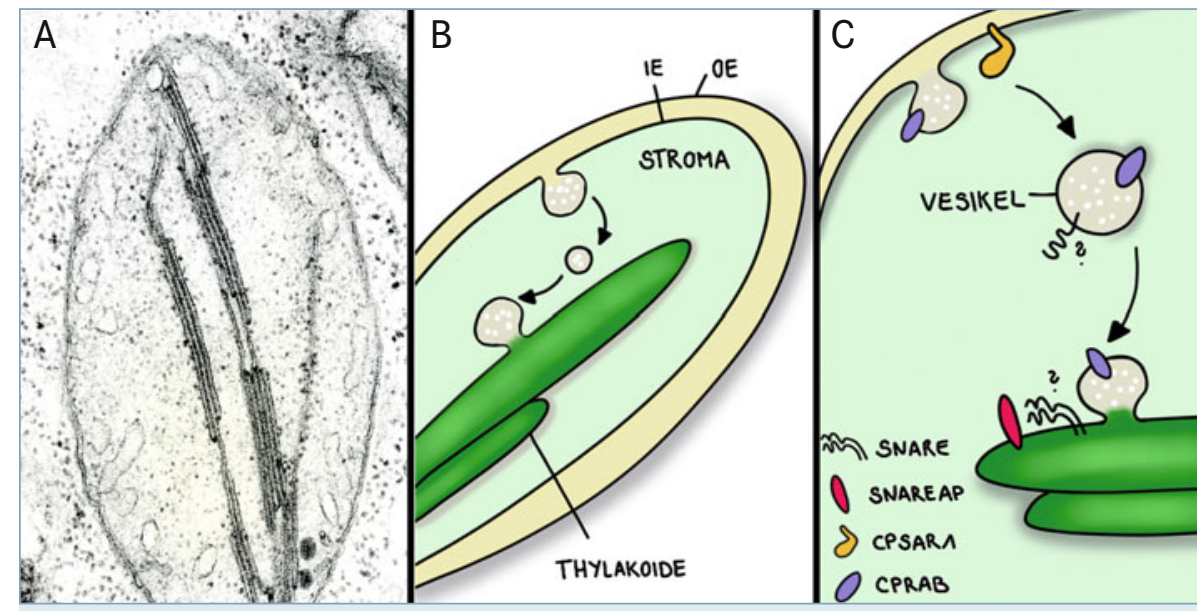

$\Delta$ Abb. 1: Plastidäre Vesikel als möglicher Transportweg durch das Stroma. Viele der benötigten Bausteine für die Thylakoide werden an der inneren Hüllmembran (IE) synthetisiert oder müssen aus dem Cytosol über beide Hüllmembranen (OE [äußere] und IE) importiert werden. Eine Hypothese, wie hydrophobe Komponenten das wässrige Stroma durchqueren könnten, bildet der plastidäre Vesikeltransport. Bisher wurden nur wenige Proteine als potenzielle Funktionsträger dieses Prozesses experimentell verifiziert. Neben SNARE AP, welches zusammen mit SNARE-Proteinen bei der Vesikelfusion an der Thyalkoidmembran beteiligt sein könnte, wird vermutet, dass kleine GTPasen wie cpSAR1 und cpRab Abschnürungs- und Andockprozesse der plastidären Vesikel regulieren könnten. A, elektronenmikroskopische Aufnahme sich akkumulierender Vesikel im Stroma. B, Schema über den plastidären Vesikeltransport. C, vermutete Lokalisierung von cpSAR1, cpRab, SNAREs und SNARE AP als potenzielle Regulatoren.
Wassers. Die Besiedelung dieses neuen Habitats erforderte enorme Anpassungen und könnte daher einer der Gründe für die Etablierung eines Vesikeltransportsystems sein [3].

Eines der mutmaßlich in den plastidären Vesikeltransport involvierten Proteine ist das SNARE-assoziierte Protein (SNARE AP) aus Arabidopsis thaliana. SNARE AP wurde als ein Protein mit vorhergesagtem Transitpeptid sowie mit Sequenzähnlichkeiten zu Tvp38 in Hefe und DedA in Bakterien identifiziert [4]. Proteine der Tvp38/DedA-Familie spielen in Bakterien eine Rolle bei der Membranorganisation, der Stabilisierung, dem Transport und der Fusion innerhalb der Zelle [5]. Basierend darauf wird angenommen, dass SNARE AP die Komplexformation der SNARE-Proteine bei der Vesikelfusion an der Thylakoidmembran unterstützt.

Bisher konnte unsere Arbeitsgruppe zeigen, dass SNARE AP tatsächlich in den Thylakoiden lokalisiert ist. Der Verlust des Proteins in Mutanten führt zu einem blassgrünen Phänotyp der Blätter mit geringerer photosynthetischer Aktivität sowie einer abnormen Thylakoidstruktur. Da es bisher allerdings keinen experimentellen Beweis für die Existenz von SNARE-Proteinen in der Thylakoidmembran gibt, bleibt die weitere Suche nach der Funktion von SNARE AP für den Chloroplasten spannend.

\section{Literatur}

[1] Gould SB, Waller RF, McFadden GI (2008) Plastid evolution. Annu Rev Plant Biol 59:491-517

[2] Westphal S, Soll J, Vothknecht UC (2001) A vesicle transport system inside chloroplasts. FEBS Lett 506:257-261 [3] Westphal S, Soll J, Vothknecht UC (2003) Evolution of chloroplast vesicle transport. Plant Cell Physiol 44:217-222 [4] Khan NZ, Lindquist E, Aronsson H (2013) New putative chloroplast vesicle transport components and cargo proteins revela us revealed using a bioinform

[5] Keller R, Schneider D (2013) Homologs of the yeast Tvp38 vesicle-associated protein are conserved in chloroplasts and cyanobacteria. Front Plant Sci 4:467

Korrespondenzadresse:

Annabel Mechela

Department Biologie I - Pflanzenwissenschaften Biozentrum der LMU München

Großhaderner Straße 2-4

D-82152 Planegg-Martinsried

Tel.: 089-2180-74767

Annabel.Mechela@campus.Imu.de 